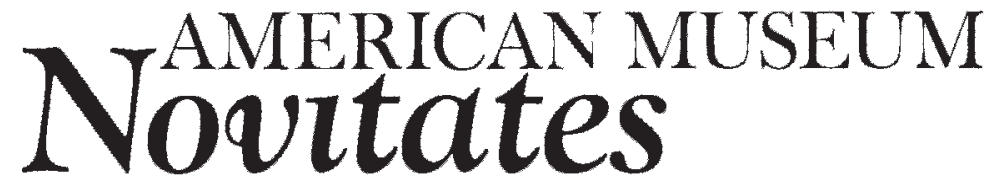

PUBLISHED BY THE AMERICAN MUSEUM OF NATURAL HISTORY CENTRAL PARK WEST AT 79TH STREET, NEW YORK, NY 10024 Number 3675, 13 pp., 26 figures

March 4, 2010

\title{
The Male Genital System of Goblin Spiders: Evidence for the Monophyly of Oonopidae (Arachnida: Araneae)
}

\author{
MATTHIAS BURGER ${ }^{1}$ AND PETER MICHALIK ${ }^{2}$
}

\begin{abstract}
The male reproductive system of spiders consists of paired, tubular testes and often long and convoluted deferent ducts, which are fused near the genital opening to form an ejaculatory duct. In rare cases and as revealed in previous studies the testes can be partly fused (anteriorly or posteriorly), as reported, for example, for Dysderidae (Dysderoidea). In order to determine whether this pattern is also present in other dysderoids, we studied the genital system of Oonopidae for the first time by means of light microscopy. The following species were included, covering both conventionally recognized subfamilies (Gamasomorphinae and Oonopinae): Neoxyphinus ogloblini Birabén, 1953; Silhouettella loricatula (Roewer, 1942); Opopaea recondita Chickering, 1951; Myrmopopaea sp.; Scaphiella hespera Chamberlin, 1924; Lionneta sp.; Orchestina moaba Chamberlin and Ivie, 1935; Oonops balanus Chickering, 1971, and Stenoonops reductus (Bryant, 1942). In contrast to other spider taxa observed to date, all studied goblin spiders possess an unpaired (completely fused) testis, which seems to be a synapomorphic trait for Oonopidae supporting the monophyly of the family. The deferent ducts of goblin spiders are mostly convoluted and of varying diameter whereas the ejaculatory duct is very small. Moreover, we found a remarkable diversity in the organization of the testis and spermatozoa, which underlines the high potential of the reproductive system for systematic studies on Oonopidae as well as other dysderoids. The putative sister group of Oonopidae is Orsolobidae; since the organization of the male genital system of orsolobids is unknown as well, we included one species (Ascuta media Forster, 1956) in the present study. It possesses the typical genital organization for male spiders represented by paired and unfused tubular testes.
\end{abstract}

\footnotetext{
${ }^{1}$ Division of Invertebrate Zoology, American Museum of Natural History (burgermatthias@hotmail.com).

${ }^{2}$ Zoologisches Institut und Museum, Ernst-Moritz-Arndt-Universität, J.-S.-Bach-Straße 11/12, D-17489 Greifswald, Germany (michalik@uni-greifswald.de).
} 


\section{INTRODUCTION}

The internal male genital system of spiders shows structural diversity across all main taxa (Michalik, in press). In general, it can be divided into three parts: paired testes, paired deferent ducts and an unpaired ejaculatory duct (e.g., Bertkau, 1875; Crome, 1951; Kim et al., 1993). From this general organization several modifications have been reported that are mainly related to the fusion of parts of the testes, such as the anterior fusion in mesothelid spiders (Michalik, 2007) and the posterior fusion in dysderids (Michalik, in press). But other parts can also differ in their morphology, such as the seminal vesicle adjacent to the ejaculatory duct peculiar to certain theridiid spiders (Michalik, in press). Thus, phylogenetically informative characters can be expected. In the present study, we focus on the morphology of the male genital system of Oonopidae for the first time.

Oonopids are a highly diverse spider family widespread in many habitats on all continents except Antarctica (e.g., Saaristo, 2001). Despite their diversity and common occurrence few studies have dealt with the phylogenetic relationships of Oonopidae. Forster and Platnick (1985) did propose the monophyly of the haplogyne superfamily Dysderoidea, which includes the four families Dysderidae, Segestriidae, Orsolobidae, and Oonopidae, and this relationship was confirmed by the more recent phylogenetic analysis by Platnick et al. (1991). Nevertheless, according to those authors the relationships within the Dysderoidea as well as the monophyly of Oonopidae remain uncertain (although a sister-group relationship between Orsolobidae and Oonopidae was favored).

Within Oonopidae two subgroups are conventionally recognized based on the classification by Simon (1893): "loricati," or Gamasomorphinae, which are hard bodied and heavily sclerotized, and "molles," or Oonopinae, which are soft bodied and weakly sclerotized. These groups are often treated as subfamilies, but their monophyly is still not supported, which can be explained by a lack of comparative studies (see also Saaristo, 2001). Moreover, Chamberlin and Ivie (1942) highlighted the distinctiveness of the genus Orchestina from other oonopid genera by erecting the subfamily Orchestininae, a hy- pothesis that was not further considered in subsequent studies.

Recent studies on the female genital system revealed a high diversity and complexity that also bear a high phylogenetic potential (Burger et al., 2003, 2006; Fannes and Jocqué, 2008; Burger, in press $a, b)$. In order to know whether similar diversity and complexity are also present in the genital system of the males and whether there are any phylogenetic implications as indicated by the observation of other spider taxa, we studied representatives across the known oonopid subfamilies (including Orchestina). Moreover, we included one representative of Orsolobidae, to see whether there are any similarities between these putative sister taxa and to report the organization of the male genital system for this spider family for the first time.

\section{List of AbBreviations}

$\begin{array}{ll}\text { BL } & \text { book lung } \\ \text { DD } & \text { deferent duct } \\ \text { ED } & \text { ejaculatory duct } \\ \text { GO } & \text { genital opening } \\ \text { LuT } & \text { lumen of testis } \\ \text { MG } & \text { midgut } \\ \text { Mu } & \text { muscles } \\ \text { N } & \text { nucleus of spermatid/spermatozoa } \\ \text { SG } & \text { silk gland } \\ \text { Sp } & \text { spermatozoa } \\ \text { Te } & \text { testis } \\ \text { TT } & \text { tracheal tube }\end{array}$

\section{MATERIALS AND METHODS}

\section{Examined Material}

Oonopidae, Gamasomorphinae: Neoxyphinus ogloblini: $1 \hat{\jmath}$, Argentina, Misiones, P. N. Iguazú, 25 - 26 October 1995, leg. M. Ramirez. Silhouettella loricatula: 2 oे, Spain, Tarragona, sifted leaf litter of freestanding carob trees (Ceratonia siliqua L.), 29-31 March 2003, leg. M. Burger and C. Kropf; 2 o, Greece, Crete, Knossos, leg. P. R. Deeleman. Opopaea recondita: 1 $\hat{\delta}, \mathrm{PBI}_{-}$ OON 00027489, USA, Florida, Monroe, Upper Matecumbe Key, Islamorada, mi 80, hammock forest litter, 30 August 1986, 86-84, leg. S. and J. Peck; 2 sे, PBI_OON 00026414, Barro Colorado Island, Canal Zone, May 1964, Museum of Comparative Zoology, MCZ 
unique no. 72448. Myrmopopaea sp.: 1 §, PBI_ OON 00006267, BB010, Australia, Queensland, footprint scrub, site I., pitfall, vine scrub, $19^{\circ} 41^{\prime} \mathrm{S}, \quad 146^{\circ} 26^{\prime} \mathrm{E}, \quad 8$ December 2006-10 February 2007, leg. G. Monteith and D. Cook. Scaphiella hespera: 2 s, PBI_OON 00026620, USA, California, Riverside, Andreas Canyon, near Palm Springs, 26 March 1960, leg. W. J. Gertsch, W. Ivie and R. Schrammel. Lionneta sp.: 1 oे, PBI_OON 00002005, DU249, Madagascar, Mahajanga, Réserve d'Ankoririka, $10.6 \mathrm{~km} \quad 13^{\circ} \mathrm{NE}$ Tsaramandroso, $16^{\circ} 16^{\prime} 2^{\prime \prime} \mathrm{S}, 46^{\circ} 2^{\prime} 55^{\prime \prime} \mathrm{E}, 210 \mathrm{~m}$, tropical dry forest, EF19 sifted litter, 9-14 April 2001, leg. B. Fisher, C. Griswold et al., California Academy of Sciences, BLF3664.

OONOPIDAe, OONOPINAE: Orchestina moaba: 1 s, USA, California, Santa Monica, 19 December 1933, leg. W. Ivie, 118.34. Oonops balanus: 2 oे, Bahamas, S Bimini, May 1951, leg. W. J. Gertsch and M. A. Cazier, Museum of Comparative Zoology. Stenoonops reductus: 2 o, PBI_OON 00027516, Virgin Islands, St. Croix, Frederiksted, Lavaetz gardens, 24 March 1964, Museum of Comparative Zoology, MCZ unique no. 71646, leg. A. M. Chickering.

OrsolobidaE: Ascuta media: 1 s, New Zealand, South Island, Fiordland, Te Anau, $200 \mathrm{~m}$, berlese litter, dry open forest, 24 March 1987, leg. N. I. Platnick and R. R. Forster.

The material is deposited in the American Museum of Natural History (AMNH), New York, USA; the Museum of Comparative Zoology (MCZ), Cambridge, USA; the Natural History Museum of Bern (NMBE), Switzerland ( $S$. loricatula), and the Museo Argentino de Ciencias Naturales (MACN), Buenos Aires, Argentina (N. ogloblini).

\section{Light Microscopy}

The opisthosomas of the males were dehydrated in ethanol, embedded in LR White Resin (soft grade acrylic London resin), and semithin serially sectioned $(1 \mu \mathrm{m})$ with a microtome (Sorvall JB-4; S. loricatula sectioned with a Leica RM2145) using glass knives. The sections were stained with toluidine blue $(1 \%)$ in an aqueous borax solution (1\%) at approximately $90^{\circ} \mathrm{C}$ for $1-4 \mathrm{~min}$. Light microscopic studies were performed with a Leica DM2500 (S. loricatula examined with a Zeiss Axioplan 2). Photos of the sections were taken with a Leica DFC 500 digital camera and edited using Adobe Photoshop Elements 2.0.

In order to get an overview of the whole genital system, males of Neoxyphinus ogloblini were dissected in phosphate buffer $(0.1 \mathrm{M}$, $\mathrm{pH}$ 7.2) and the genital system was isolated. Photos were taken with a digital camera Nikon DXM1200 mounted on a stereoscopic microscope Nikon SMZ1500.

\section{RESULTS}

The gross morphology of the male genital system is very similar in all observed oonopid species. In general, it consists of an unpaired (completely fused) testis and two short and often convoluted deferent ducts, which fuse near the genital opening to form a small ejaculatory duct (figs. 1, 26). In the testes of all observed species different stages of spermatogenesis are present (figs. 3, 7, 10, 14, 16, 17, 20, 22, 25) and the spermatozoa are characterized by remarkable structural diversity.

\section{Oonopidae, Gamasomorphinae}

Neoxyphinus ogloblini (figs. 1-4): The testis of the examined specimen of $N$. ogloblini is very large relative to the opisthosoma size (figs. 1,2). The thick deferent ducts are short and convoluted (fig. 4). In the periphery of the testis early stages of spermatogenesis are present whereas toward the center late spermatids are prominent (fig. 2). The nuclei of the late spermatids and spermatozoa are highly elongated and curved or twisted (fig. 3). At the end of spermatogenesis, the spermatozoa form aggregates (transfer forms) that are present in the deferent ducts (figs. 3, 4).

Silhouettella loricatula (figs. 5-8): As in the previous species the testis is very large and the thick deferent ducts are convoluted (figs. 5, 6). No significant intraspecific variation in size and position of the testis was observed in the investigated specimens. Different stages of spermatogenesis could be observed, but the cysts of the developing stages are less stratified than in N. ogloblini (figs. 5, 6). The lumen of the testis is very small and contains few aggregated spermatozoa (figs. 6, 7). In the periphery the 

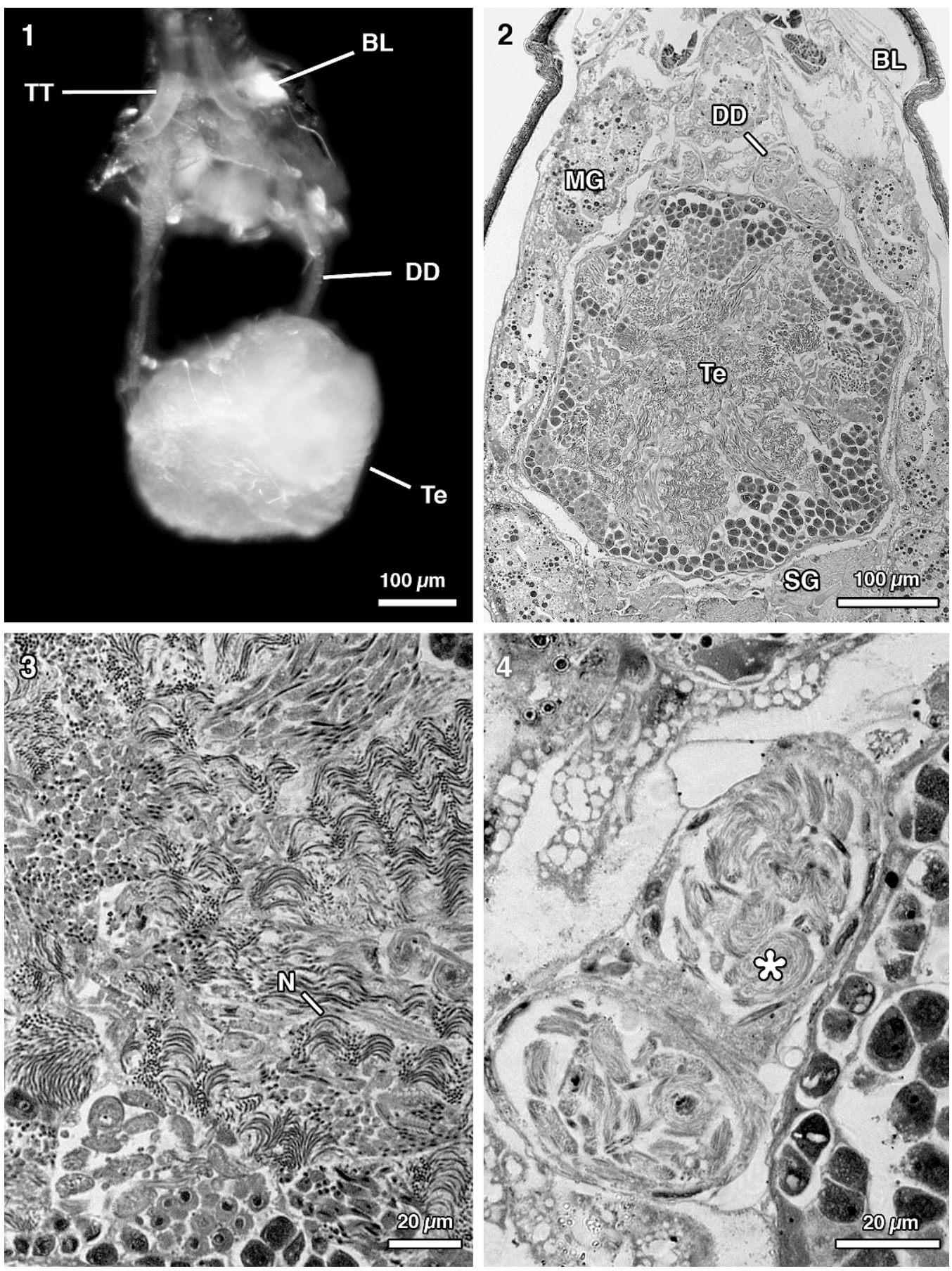

Figs. 1-4. Neoxyphinus ogloblini. 1. Dorsal view of the male genital system. 2. Horizontal section of the male opisthosoma. 3. Detail of the testis showing the different stages of spermatogenesis. 4. Detail of the deferent duct showing the sperm aggregates (transfer form, asterisk). 

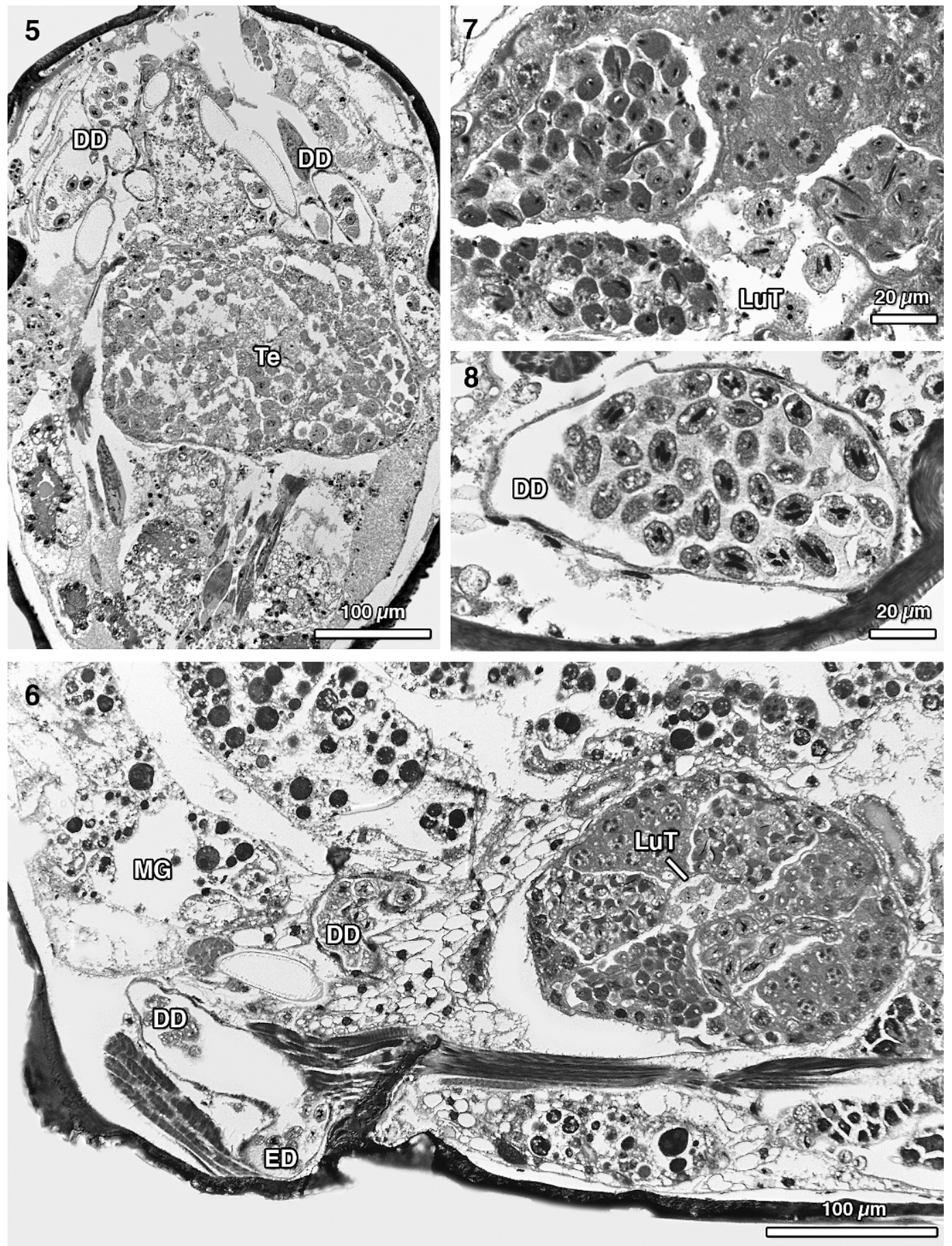

Figs. 5-8. Silhouettella loricatula. 5. Horizontal section of the male opisthosoma. 6. Longitudinal section of the male opisthosoma. 7. Detail of the testis showing the different stages of spermatogenesis. 8. Detail of the deferent duct showing the sperm aggregates (transfer form). 

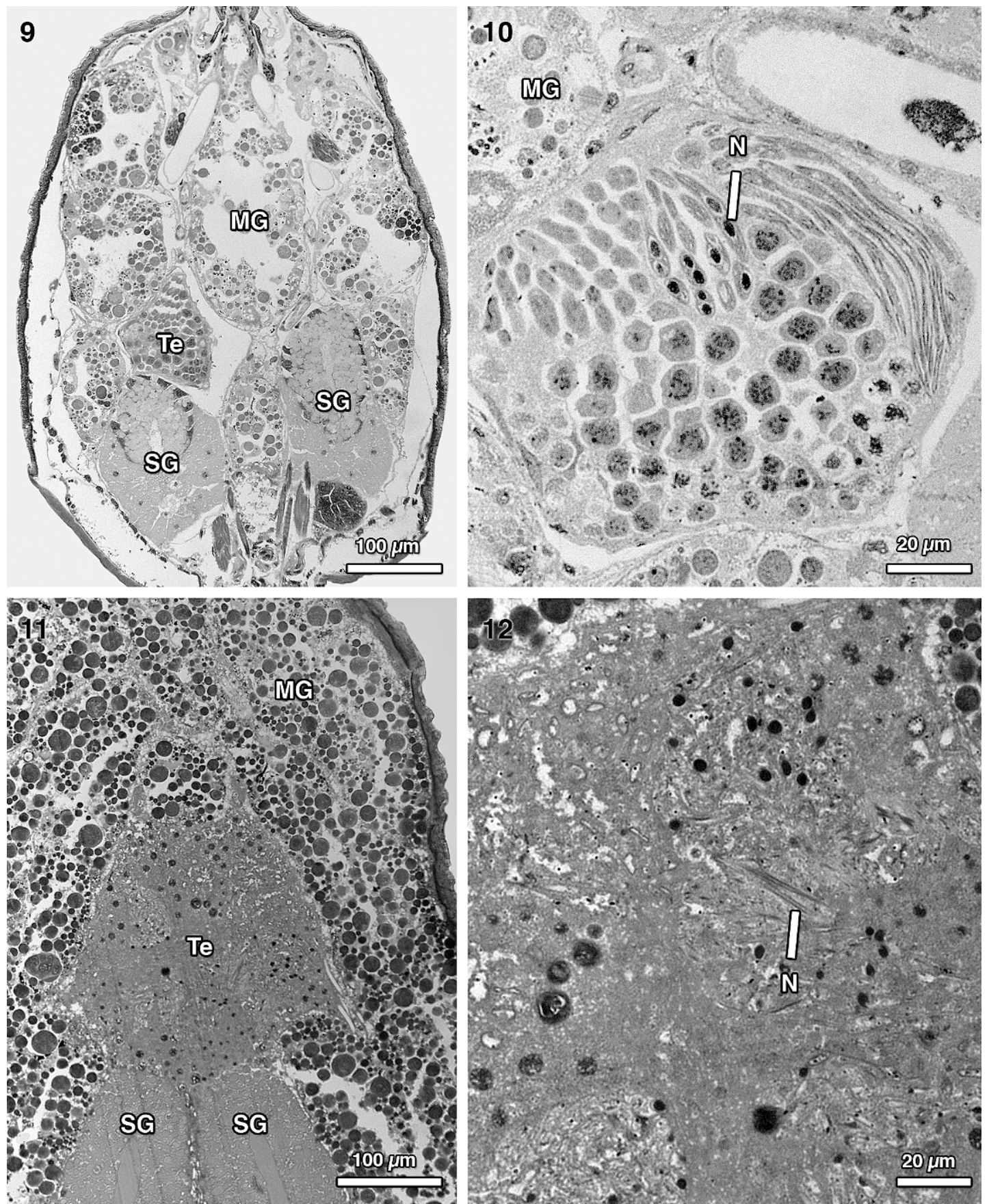

Figs. 9-10. Opopaea recondita. 9. Horizontal section of the male opisthosoma. 10. Detail of the testis showing the different stages of spermatogenesis. Figs. 11-12. Myrmopopaea sp. 11. Horizontal section of the male opisthosoma. 12. Detail of the testis showing the different stages of spermatogenesis. 

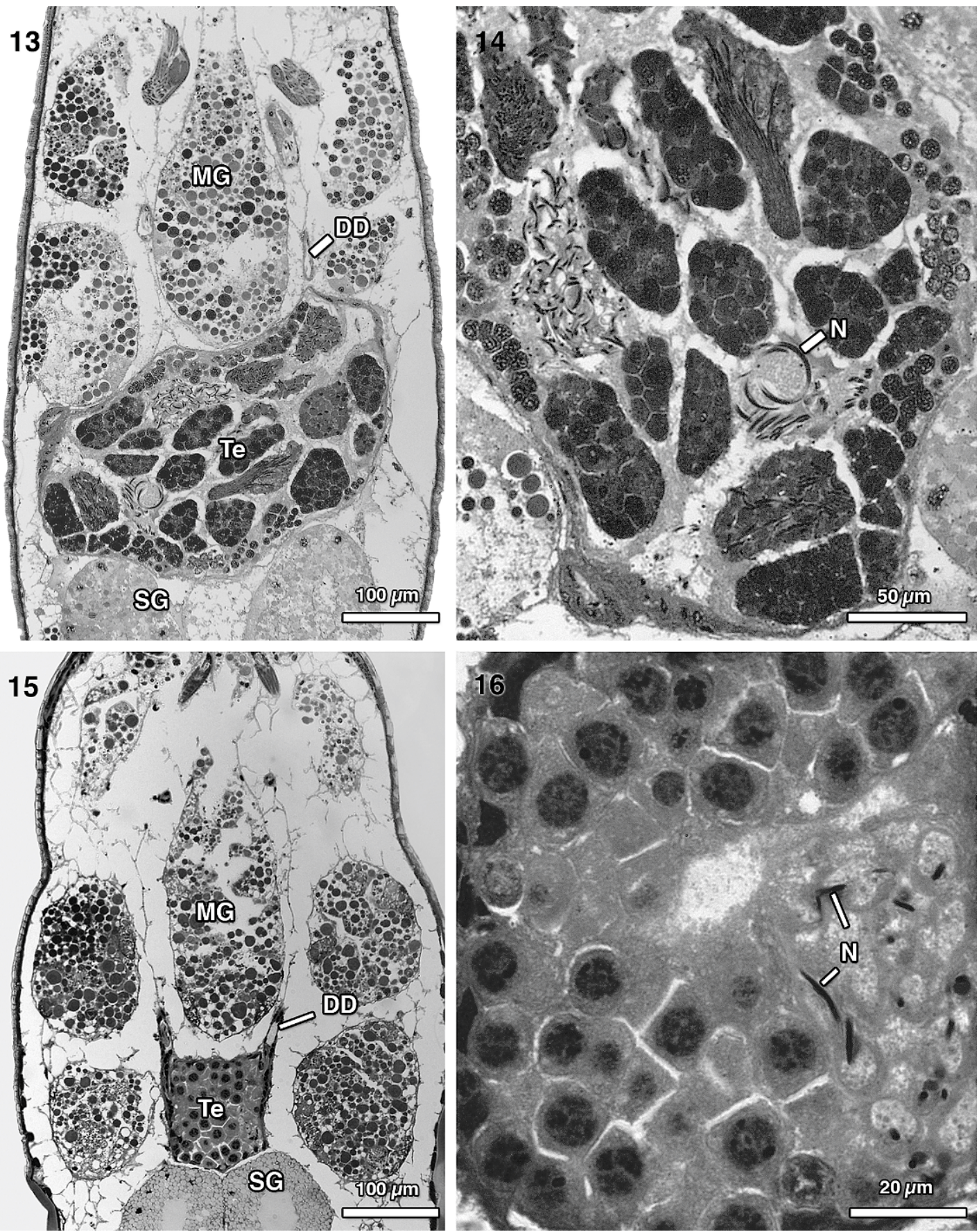

Figs. 13-14. Scaphiella hespera. 13. Horizontal section of the male opisthosoma. 14. Detail of the testis showing the different stages of spermatogenesis. Figs. 15-16. Lionneta sp. 15. Horizontal section of the male opisthosoma. 16. Detail of the testis showing the different stages of spermatogenesis. 

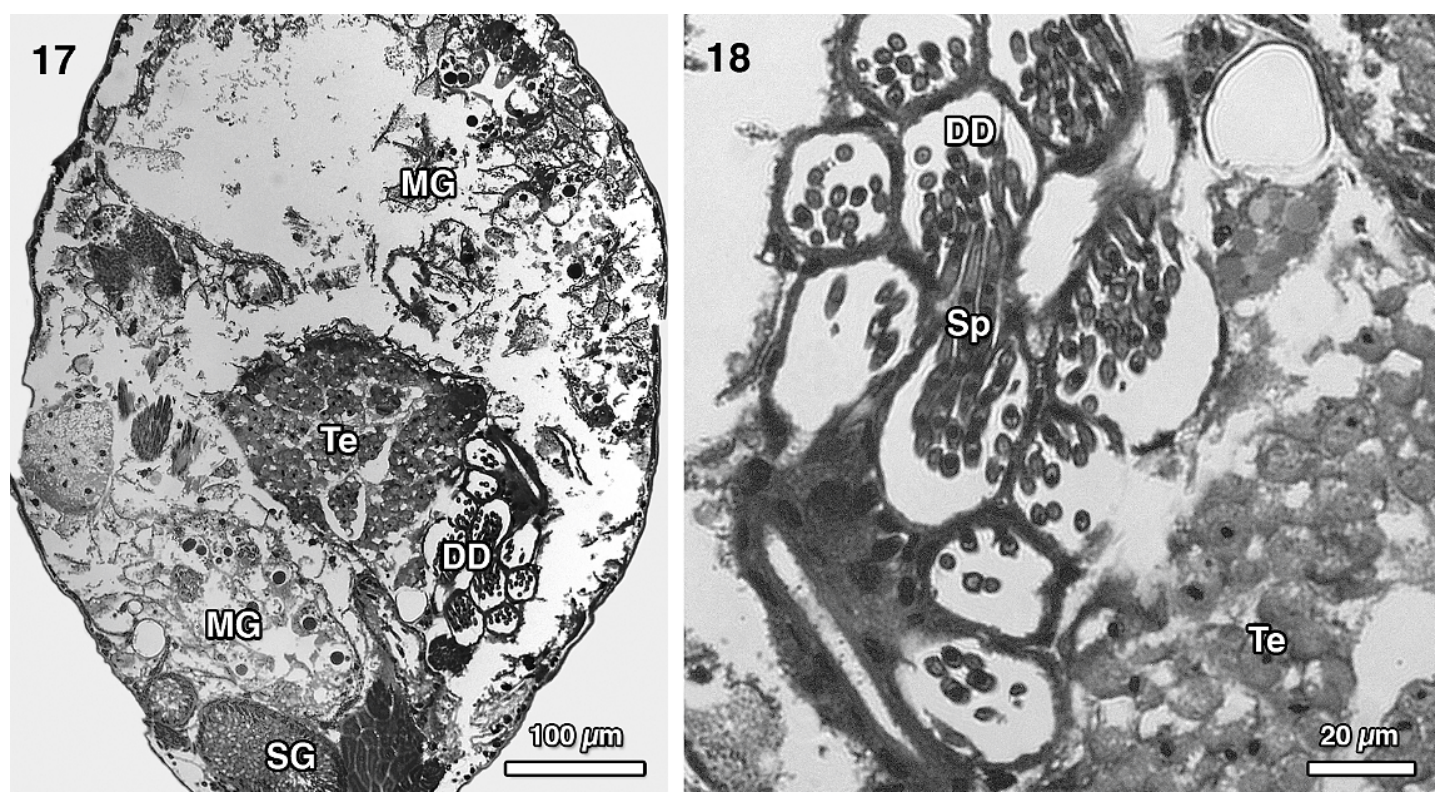

Figs. 17-18. Orchestina moaba. 17. Horizontal section of the male opisthosoma. 18. Detail of the deferent duct showing the mature spermatozoa.

somatic cells are clearly visible (fig. 7). The spermatids are mostly roundish with an elongated nucleus (fig. 7). In the deferent ducts oval transfer forms are present (fig. 8).

Opopaea recondita (figs. 9-10): The testis of $O$. recondita is very different from that of other examined species. It is restricted to one body side and remarkably small (fig. 9). No significant intraspecific variation in size and position of the testis was observed in the investigated specimens. Deferent ducts have not been observed until now (this might be due to insufficient fixation of the material). Within the testis only a few spermatids/ spermatozoa of different developmental stages are present (fig. 10). The late spermatids/ spermatozoa are highly elongated (fig. 10).

Myrmopopaea sp. (figs. 11-12): In contrast to $O$. recondita, the small, unpaired testis in the examined specimen of Myrmopopaea sp. is located in the center of the opisthosoma (fig. 11). It possesses an $\mathrm{H}$-shape in the ventral part, which continues in the thin and only slightly convoluted deferent ducts. Within the testis different stages of spermatogenesis are present, such as elongated late spermatids (fig. 12). Due to insufficient fixation of the material no further interpretation can be given.

Scaphiella hespera (figs. 13-14): The testis is very large and nearly as wide as the opisthosoma (fig. 13). No significant intraspecific variation in size and position of the testis was observed in the examined specimens. The deferent ducts are very thin and only slightly convoluted. The spermatogenesis occurs as usual in cysts, which are not stratified and are very conspicuous due to the dense material in the intercellular space (figs. 13, 14). The thin nuclei of the spermatozoa are highly elongated and coiled in late stages (fig. 14).

Lionneta sp. (figs. 15-16): In the investigated specimen of Lionneta sp. the testis is very small and situated in the posterior part of the opisthosoma (fig. 15). The deferent ducts are very thin and slightly convoluted (fig. 15). The number of sperm cells is remarkably low and only a few late spermatids characterized by an elongated thin nucleus were observed (fig. 16).

\section{Oonopidae, Oonopinae}

Orchestina moaba (figs. 17-18): The testis of the investigated specimen of $O$. moaba is very 

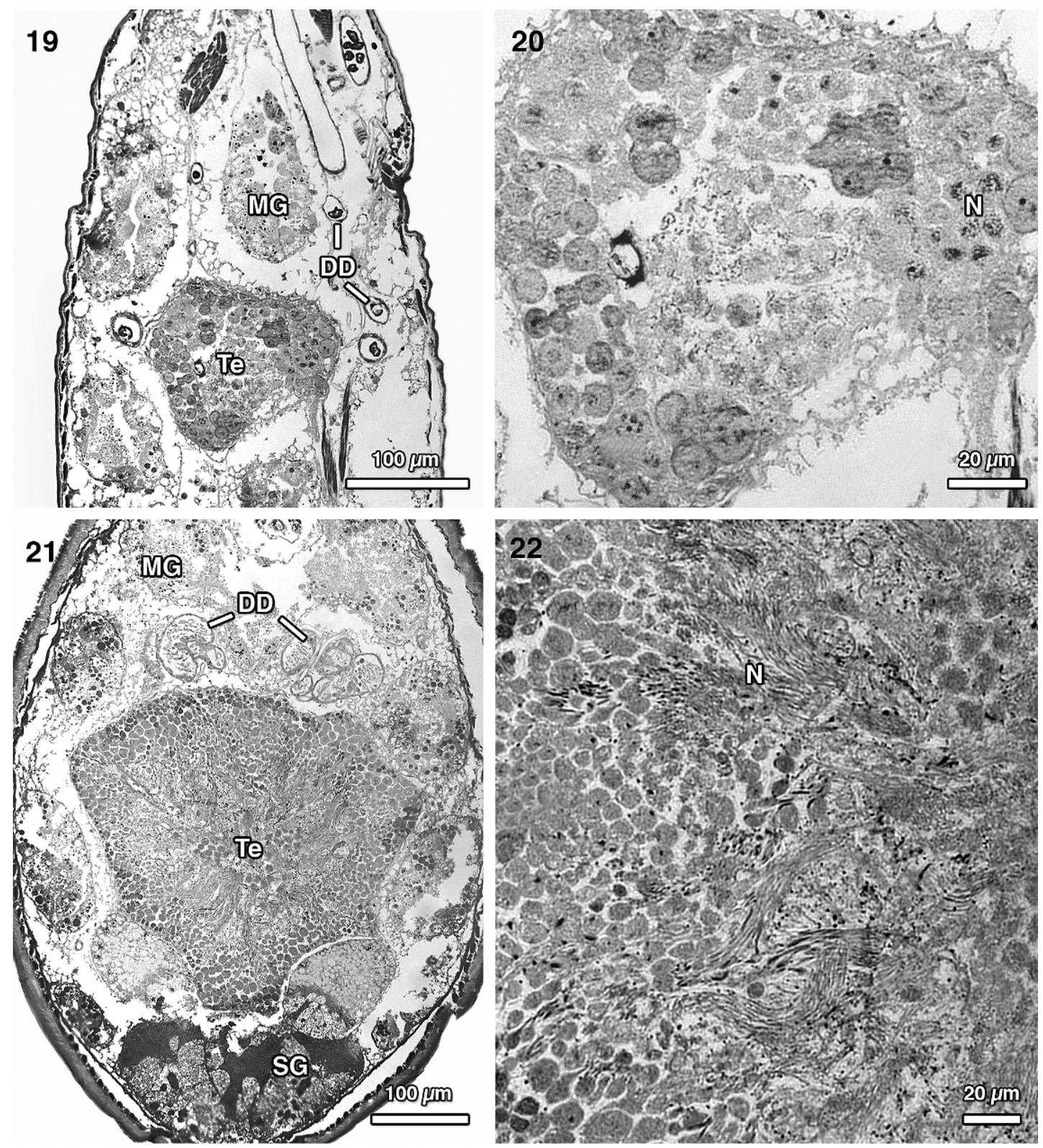

Figs. 19-20. Oonops balanus. 19. Horizontal section of the male opisthosoma. 20. Detail of the testis showing the different stages of spermatogenesis. Figs. 21-22. Stenoonops reductus. 21. Horizontal section of the male opisthosoma. 22. Detail of the testis showing the different stages of spermatogenesis.

large and increases in size toward the dorsal part of the opisthosoma (fig. 17). The deferent ducts are strongly convoluted and filled with highly ordered elongated spermatozoa (fig. 18). In the testis different stages of spermatogenesis are organized in cysts, but due to the limited quality of the material no further interpretation can be given.

Oonops balanus (figs. 19-20): This species is characterized by a relatively large testis and convoluted deferent ducts that sometimes appear slightly bulbous (fig. 19). No signifi- 

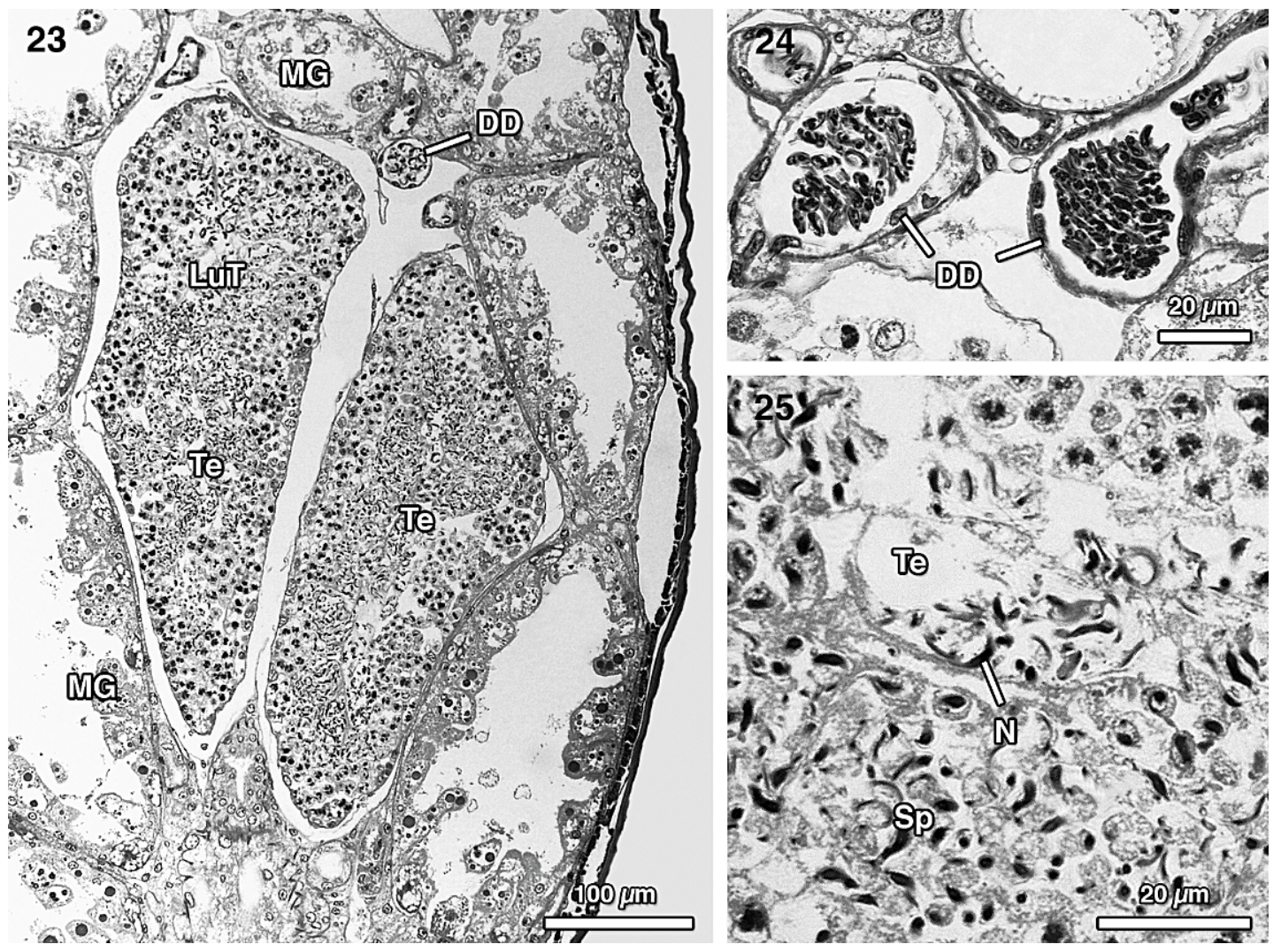

Figs. 23-25. Ascuta media. 23. Horizontal section of the male opisthosoma. 24. Horizontal section of the deferent duct showing the densely packed sperm cells. 25. Detail of the testis showing the different stages of spermatogenesis.

cant intraspecific variation in size and position of the testis was observed in the investigated specimens. The spermatids develop in cysts, which are not ordered (fig. 20). In contrast to the other species, the spermatids/spermatozoa are very compact and not elongated (fig. 20).

Stenoonops reductus (figs. 21-22): The genital system of $S$. reductus is mainly characterized by an extremely voluminous testis, which fills most of the opisthosoma (fig. 21). No significant intraspecific variation in size and position of the testis was observed in the investigated specimens. The bulbous deferent ducts are highly convoluted (fig. 21). Inside the testis different stages of spermatogenesis are present, organized in cysts that seem to be stratified, with earlier stages near the periphery and later stages toward the lumen (fig. 21).
In contrast to $O$. balanus, the late spermatids/ spermatozoa are characterized by a highly elongated nucleus (fig. 22).

\section{Orsolobidae}

Ascuta media (figs. 23-25): In contrast to observed goblin spiders, the genital system of the examined specimen of this species consists of paired and unfused testes (fig. 23). The deferent ducts are comparatively thick and convoluted (figs. 23, 24). The internal organization of the testes comprises early stages of spermatogenesis at the periphery and later spermatogenic stages toward the lumen (fig. 23). The spermatozoa are characterized by a slightly elongated nucleus that seems partly curved (fig. 25). In the deferent ducts the spermatozoa are densely packed (fig. 24). 


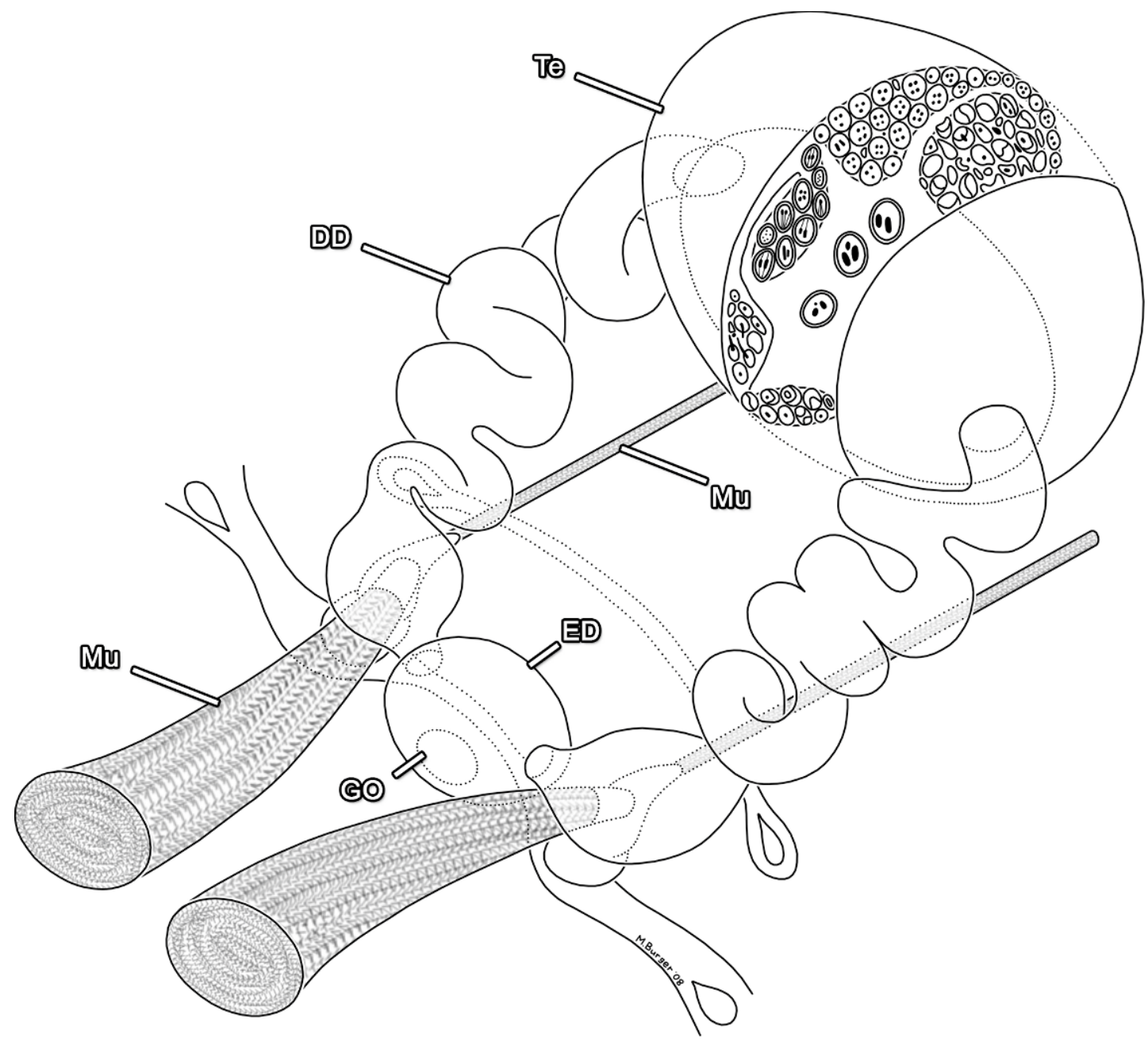

Fig. 26. Schematic reconstruction of the male genital system of Silhouettella loricatula.

\section{DISCUSSION}

Based on scanning electron microscopic observations of the tarsal organ, Forster and Platnick (1985) claimed that many austral genera previously assigned to oonopids are more closely related to Orsolobus Simon than to true oonopids. However, the systematic relationships within Oonopidae as well as their putative sister group are still obscure and no comparative studies exist dealing with phylogenetic hypotheses of Oonopidae and/or Dysderoidea (a first approach has recently started with a Planetary Biodiversity Inventory of the family Oonopidae, partly supported by the U.S. National Science Foundation).
The present study provides the first clear evidence for the monophyly of goblin spiders. All observed species belonging to different subfamilies (including Orchestina) possess an unpaired (completely fused) testis; such an arrangement is not present in any other spider family observed to date (fig. 26). In contrast, in the putative sister group Orsolobidae, paired and unfused tubular testes are present, which represents the typical organization of the male genital system of spiders (see Michalik, in press). The inner organization of the testis of all observed species is similar to what is known in other spider groups, with somatic cells in the periphery, cysts with different developmental stages of spermatids, 
and a lumen in the center containing the spermatozoa or the sperm aggregations (transfer forms). The evolution of the unpaired (completely fused) testis is still not clear. It seems likely that it evolved from partly fused testes such as those found in most of the Dysderidae (Bertkau, 1875, 1878; Michalik, in press). The assumption that the completely fused testis evolved from partly fused testes might suggest that Dysderidae could be the sister group of Oonopidae rather than Orsolobidae. Partly fused testes have also been reported from Scytodidae, and thus might be a convergent trait within haplogyne spiders (Michalik, in press).

The present study reveals a remarkable diversity in the amount and structure of sperm cells among goblin spiders. This is of special interest since recent studies have shown an astonishing diversity of sperm characters that are very promising for studies on spider phylogeny (Alberti and Weinmann, 1985; Alberti, 1990; Michalik et al., 2004; Michalik and Alberti, 2005; Michalik and Huber, 2006; Michalik et al., 2006; Michalik, 2007). For example, the only ultrastructural study on Oonopidae, dealing with the spermatozoa of Oonops domesticus, revealed a highly aberrant organization of the sperm cells (Alberti and Weinmann, 1985). They are characterized by a very compact nucleus, which possesses a conspicuous short postcentriolar elongation. The spermatozoa of this species are finally transferred as cleistospermia. This is in accordance with our findings on Oonops balanus. Based on our light microscope observations, a fundamentally different organization of the spermatozoa between Oonops balanus and Oonops domesticus can be excluded. Instead, the other observed species are clearly different from what is described for Oonops. In those species, the nucleus is mostly (extremely) elongated and the spermatozoa are highly ordered and aggregated in the deferent ducts (where the transfer forms are formed/stored). This is also in accordance with our preliminary ultrastructural observations of Neoxyphinus ogloblini and Silhouettella loricatulathe organization of the nucleus of these species is very different from Oonops but also from each other (Michalik and Burger, personal obs.). Moreover, these species possess syn- spermia as transfer forms, which are also present in all other dysderoids (Alberti and Weinmann, 1985; Michalik et al., 2004; Michalik, personal obs.). To conclude, there are not only clear differences in sperm structure between but also within the subfamilies of oonopids (e.g., Oonops vs. Stenoonops). Thus, it seems likely that detailed ultrastructural studies on the spermatozoa and spermatogenesis will reveal many characters of phylogenetic importance.

Another conspicuous finding concerns the amount of spermatozoa produced in the testis. In species producing a large amount of spermatozoa (e.g., Stenoonops reductus and Scaphiella hespera) the females also possess very large receptacula (Burger, in press a), which is in contrast to species with a small testis (e.g., Opopaea recondita) where the females can even have no distinct sperm storage organ (Burger, in press a). Recent studies have already revealed a high complexity in the female genitalia and reproductive biology of oonopids (Burger et al., 2003, 2006; Burger, 2007; Fannes and Jocqué, 2008; Burger, in press a, b). For example, the female of Silhouettella loricatula is characterized by a large receptaculum where the transferred male seminal fluid is enclosed in large amounts of secretions, forming a distinct sac (Burger et al., 2006). Interestingly, the sac can be dumped in subsequent copulations, which may allow females to bias sperm precedence (Burger, 2007).

\section{ACKNOWLEDGMENTS}

The authors wish to thank Martin J. Ramirez and Facundo Labarque (MACN, Buenos Aires, Argentina) for providing the Neoxyphinus material. Furthermore, we are very grateful to Norman I. Platnick (AMNH, New York, USA) and Bernhard A. Huber (ZFMK, Bonn, Germany) for valuable comments on the manuscript. This study was supported by the U. S. National Science Foundation for a Planetary Biodiversity Inventory of the spider family Oonopidae (award no. DEB-0613754 for M.B.), the German National Merit Foundation (grant to P.M.) and the German Research Council (DFG, Al 138/11-1). 


\section{REFERENCES}

Alberti, G. 1990. Comparative spermatology of Araneae. Acta Zoologica Fennica 190: 17-34.

Alberti, G., and C. Weinmann. 1985. Fine structure of spermatozoa of some labidognath spiders (Filistidae, Segestriidae, Dysderidae, Oonopidae, Scytodidae, Pholcidae; Araneae; Arachnida) with remarks on spermiogenesis. Journal of Morphology 185: 1-35.

Bertkau, P. 1875. Über den Generationsapparat der Araneiden. Archiv für Naturgeschichte 41: 235-262.

Bertkau, P. 1878. Versuch einer natürlichen Anordnung der Spinnen nebst Bemerkungen zu einzelnen Gattungen. Archiv für Naturgeschichte 44 (1): 351-409.

Burger, M. 2007. Sperm dumping in a haplogyne spider. Journal of Zoology 273: 74-81.

Burger, M. In press a. Female genitalia of goblin spiders (Arachnida: Araneae: Oonopidae): a morphological study with functional implications. Invertebrate Biology

Burger, M. In press b. Complex female genitalia indicate sperm dumping in armored goblin spiders (Arachnida, Araneae, Oonopidae). Zoology

Burger, M., W. Graber, P. Michalik, and C. Kropf. 2006. Silhouettella loricatula (Arachnida, Araneae, Oonopidae): a haplogyne spider with complex female genitalia. Journal of Morphology 267: 663-677.

Burger, M., W. Nentwig, and C. Kropf. 2003. Complex genital structures indicate cryptic female choice in a haplogyne spider (Arachnida, Araneae, Oonopidae, Gamasomorphinae). Journal of Morphology 255: 80-93.

Chamberlin, R.V., and W. Ivie. 1942. A hundred new species of American spiders. Bulletin of the University of Utah 32 (13): 1-117.

Crome, W. 1951. Die grobe Morphologie des männlichen Genitalapparates einiger Araneen. Deutsche Zoologische Zeitschrift 1 (3): 169-186.

Fannes, W., and R. Jocqué. 2008. Ultrastructure of Antoonops, a new, ant-mimicking genus of Afrotropical Oonopidae (Araneae) with complex internal genitalia. American Museum Novitates 3614: 1-30.

Forster, R.R., and N.I. Platnick. 1985. A review of the austral spider family Orsolobidae (Arach- nida, Araneae) with notes on the superfamily Dysderoidea. Bulletin of the American Museum of Natural History 181 (1): 1-229.

Kim, J.K., T.H. Kim, and M.J. Moon. 1993. Ultrastructure of the testis in the spider, Pardosa astrigera L. Koch. Korean Arachnology 9: 43-53.

Michalik, P. 2007. Spermatozoa and spermiogenesis of Liphistius cf. phuketensis (Mesothelae, Araneae, Arachnida) with notes on phylogenetic implications. Arthropod Structure \& Development 36 (3): 327-335.

Michalik, P. In press. The male genital system of spiders (Arachnida, Araneae) with notes on the fine structure of seminal secretions. In C. Kropf and O. Horak (editors), Towards a natural history of arthropods and other organisms - in memoriam Konrad Thaler. Contributions to Natural History 16.

Michalik, P., and G. Alberti. 2005. On the occurence of the $9+0$ axonemal pattern in the spermatozoa of sheetweb spiders (Linyphiidae, Araneae). Journal of Arachnology 33 (2): 569-572.

Michalik, P., R. Dallai, F. Giusti, and G. Alberti. 2004. The ultrastructure of the peculiar synspermia of some Dysderidae (Araneae, Arachnida). Tissue and Cell 36 (6): 447-460.

Michalik, P., and B.A. Huber. 2006. Spermiogenesis in Psilochorus simoni (Berland, 1911) (Pholcidae, Araneae): evidence for considerable within-family variation in sperm structure and development. Zoology: 14-25.

Michalik, P., P. Sacher, and G. Alberti. 2006. Ultrastructural observations of spermatozoa of several tetragnathid spiders with phylogenetic implications (Araneae, Tetragnathidae). Journal of Morphology, 267 (2): 129-151.

Platnick, N.I., J.A. Coddington, R.R. Forster, and C.E. Griswold. 1991. Spinneret morphology and the phylogeny of haplogyne spiders (Araneae, Araneomorphae). American Museum Novitates 3016: 1-73.

Saaristo, M.I. 2001. Dwarf hunting spiders or Oonopidae (Arachnida, Araneae) of the Seychelles. Insect Systematics and Evolution 32: 307-358.

Simon, E. 1893. Histoire naturelle des araignées Vol. 1: 257-488. Paris: Roret. 